\title{
Oral Healthcare Behaviors of Dental and Non-dental Turkish Students: A Comparative Study
}

\author{
Melike Camgoz
}

\begin{abstract}
Aim and objective: Oral health education, including tooth brushing, during childhood, is important since this affects individuals' behaviors as adults. The purpose of this investigation was to assess the self-reported oral health behaviors of dental and non-dental/medical university students in Ankara, Turkey, by utilizing the Hiroshima University Dental Behavior Inventory (HU-DBI).

Materials and methods: The study population consisted of 326 students from the faculty of dentistry and 331 students from non-dental faculties. All students were at various stages of education and were surveyed using the HU-DBI. The concise prediction about oral health behavior was studied from the replies to the twelve statements. To compare the total HU-DBI score between groups, an independent sample $t$-test was conducted.

Results: Significant differences were detected among the student groups. The mean HU-DBI point of dental school students was significantly higher than non-dental students. Less dental students stated gingival bleeding, sticky deposits, being uncomfortable with the color of gums, and postponing going to a dentist if they do not have a toothache.

Conclusion: The results we obtained marked that dental students have better dental attitudes than non-dental/medical students. This may be explained by dental students' receiving dental curriculum and clinical training.

Clinical significance: Comprehensive national programs aiming to teach oral healthcare, to support individuals' oral hygiene applications, and to generalize preventive oral health information should be conducted starting from early childhood.

Keywords: Dental students, Hiroshima University Dental Behavior Inventory, Non-dental/medical students, Oral healthcare behaviors.

International Journal of Experimental Dental Science (2021): 10.5005/jp-journals-10029-1222
\end{abstract}

\section{INTRODUCTION}

Health and diseases of the oral cavity include the interaction of complicated proceedings, including various elements. In dentistry, it is obligatory to understand these elements and advance interventions to evolve the oral health of nations. ${ }^{1}$

The most efficient way to ensure oral health is to prevent oral diseases. Oral health is acknowledged to be as important as general health. The attitudes of suppliers of oral health maintenance and their oral self-care behaviors project their perception of the significance of preclusive dental operations and assists in advancing the oral health of the sufferers whom they provide treatment..$^{2-5}$ Therefore, they can be a positive control group for the studies evaluating oral health attitudes of undergraduates of other domains except medical. In addition to this, it was stated in the literature that oral self-care applications of dental students get better as their years in dental school extend. ${ }^{6-9}$ Since different countries have differences in healthcare systems and speak dissimilar languages, being able to compare the oral health behaviors and attitudes of oral healthcare suppliers from different countries may be time-consuming and/ or complicated. Consequently, to study dental health behavior, apprehension, and attitudes of the individuals, Hiroshima University Dental Behavior Inventory (HU-DBI) was developed by Dr Makoto Kawamura in $1988 .{ }^{10}$ The inventory was in Japanese originally. It is composed of 20 statements principally regarding oral health attitudes and tooth-brushing habit. All questions have a dichotomous response format (agree/disagree). A numerical prediction of entire oral health attitude and behavior is ensured by the sum number of suitable agree/disagree responses. The possible highest score that can be received is 12 , and better oral health behavior is indicated
Gazi Universitesi Dis Hekimligi Fakultesi Ogretim Uyeleri Klinigi, Biskek Cd. 1. Sk No.4 Emek/Cankaya, Ankara, Turkey

Corresponding Author: Melike Camgoz, Gazi Universitesi Dis Hekimligi Fakultesi Ogretim Uyeleri Klinigi, Biskek Cd. 1. Sk No.4 Emek/Cankaya, Ankara, Turkey, Phone: +90 31220342 10, e-mail: mlkozcan@yahoo. com

How to cite this article: Camgoz M. Oral Healthcare Behaviors of Dental and Non-dental Turkish Students: A Comparative Study. Int J Experiment Dent Sci 2021;10(1):1-7.

Source of support: Nil

Conflict of interest: None

by higher scores. ${ }^{11}$ The HU-DBI has been interpreted into many languages and as a result comparisons between different countries and cultures could be performed. ${ }^{12}$ The English version of the HU-DBI has a good currency and test-retest credibility. ${ }^{13}$

This scale has been used in several countries to investigate the oral health attitudes of dental school students. Lujo et al. studied freshmen and senior grade dental students in Croatia and found that with progression in dental training, oral health attitudes advanced, but the level of oral hygiene decreased. ${ }^{9}$ The results of a study in Turkish dental students indicated that on account of improving oral health in Turkey, more and effective oral health education is required. ${ }^{2}$ A study that was carried out to identify oral health applications of dental students reported poor oral health behaviors in Jordan. ${ }^{6}$ In a later study, Al-Omiri et al. found that as the years of study increased, dental students' oral health habits improved in some aspects. ${ }^{8}$ Nevertheless, this improvement was 
regarded insufficient and they indicated that students should be motivated to become good examples of oral health for society. Kawamura et al. investigated cultural diversions in oral health behavior, and significant differences in attitudes were discovered among first-year dental students from Japan, Hong Kong, and Western China. ${ }^{14}$ In an investigation where Japanese and Finnish dental students were compared, final-year Japanese students stated better oral health behaviors than Finnish final-year students. ${ }^{15}$ Mekhemar et al. conducted a study among preclinical and clinical dental students in Germany and did not find influential differences in oral hygiene attitudes between the two groups. ${ }^{16}$ A study was conducted to evaluate the differentiation of oral health behavior between Greek and Japanese dental students cross-culturally. The results indicated substantial differences amongst the students of these countries, resulting from various cultures having dissimilar health education systems. ${ }^{17}$ Yet, in all these studies, non-dental populations consisted of other healthcare professionals.

Oral health education, including tooth brushing, during childhood, is important since this affects individuals' behaviors as adults. University students are the educators and/or the parents of tomorrow, so their knowledge and attitudes on oral health are also very important. Currently, almost eight million students are studying in universities in Turkey. Nevertheless, there is no sufficient information on oral health attitudes and behaviors of university students in Turkey. This research aimed to evaluate the self-reported oral health behavior and attitudes of a population consisting of non-dental/medical university students in Ankara, Turkey, and to compare their oral health behavior and attitudes with sex, age, and socioeconomic status balanced preclinic and clinic dental students as control groups by utilizing the HU-DBI.

\section{Materials and Methods}

There were two stages of linguistic equivalence: (1) translation and back translation of the inventory and (2) equivalence testing between the Turkish and English versions of the survey form. First, bilingual dental professionals translated the English form of the questionnaire into Turkish. At the same time, a bilingual psychologist translated the survey separately to give the same impression for the items. These were then compared and discussed with two bilingual Turkish professionals proficient in epidemiological researches and questionnaires. After reaching a satisfactory agreement in regard to the translated format, the Turkish inventory was back-translated. Afterward, the items in Turkish were translated into English by a bilingual English teacher, who had not seen the original version. Next, a comparison between the translated Turkish, and the original English inventory was made by the investigator. Minor alterations in the definitions of some statements were performed with the help of the back translator. A Turkish language specialist controlled the grammar and the sentence structures and made the necessary minor corrections in the Turkish version.

At the second stage, in a convenience sample of eight bilingual dental research assistants, the linguistic equivalence of the original English HU-DBI to the Turkish version was validated. Cohen's kappa test was used to test item agreements between the two versions in English and Turkish. ${ }^{18}$ The range of kappa coefficients of the 20 items between 0.64 and 0.92 .

The study population consisted of 326 students from Ankara University Faculty of Dentistry and 331 students from non-dental faculties of Gazi University, Ankara (Table 1). All students were at various stages of education and were surveyed by using the HU-DBI.

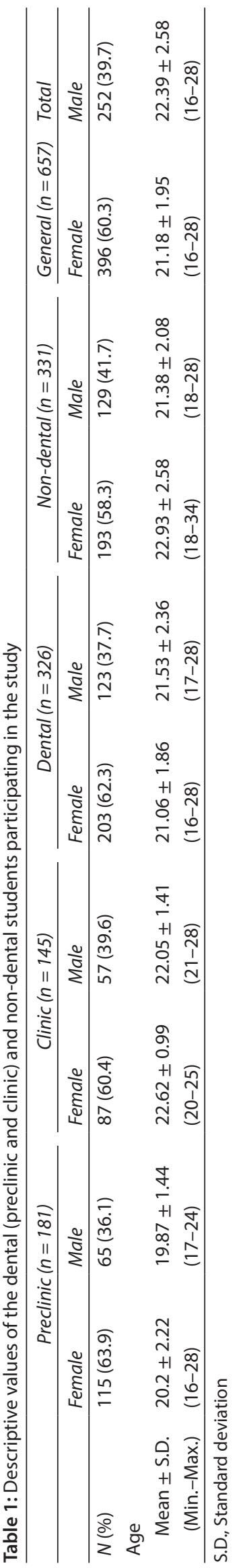


The dental students completed the questionnaire in their classrooms altogether, whereas, for the non-dental group, the participants were surveyed when they applied for a dental examination. Every 10th student who applied for a dental examination was surveyed during the same day. All students participated voluntarily and signed the informed consent, although survey procedures had an exemption from institutional review boards in the year that the data were collected; the research was performed in accordance with the Declaration of Helsinki. The survey was completed anonymously, and age, gender, name of the school, place of birth, and economic status of the parents were collected.

\section{Statistical Analysis}

The differentiation in the distribution of all variables by the group was evaluated using the Chi-square test. First, to compare the answers of preclinical and clinical students, univariate analyses were conducted. Next, to construct multivariate logistic regression models with group status as a dependent variable, a step-wise backward selection strategy was utilized. The Wald statistic was used to test the null hypothesis if the regression coefficients were zero. The sum of oral health behavior prediction was calculated using the replies of the predetermined items. ${ }^{19}$ To compare the total HU-DBI scores between groups; an independent sample $t$-test was performed. Materials were analyzed using the SPSS 10.0 (SPSS. Inc. Chicago, IL, USA) package, and the statistical significance was considered $p<0.05$.

\section{Results}

The mean age was $21.24 \pm 2.07$ for dental school students and $22.30 \pm 2.5$ for non-dental students (Table 1). Table 2 shows the rate of "agree" responses in the HU-DBI. The data are grouped by sub-groups of the dental students. Significant differences were discovered between the student groups. The mean HU-DBI scores, number of teeth with fillings and extracted teeth; and percent of satisfaction with appearance for the groups are shown in Table 2.

About $43 \%$ of the dental students said they had postponed visiting a dentist till they suffered from toothache (Item 15) and $73.3 \%$ reported that they believe it was not possible to prevent periodontal diseases by only tooth brushing (Item 14). Sixty-nine percent of all dental students did not have worries about visiting the dentist and $67 \%$ stated brushing each tooth meticulously (Item 1). More preclinical students than clinical students had never been taught how to brush by a dental professional (Item 10, $p<0.001$ ) and they were using toothbrush with hard bristles (Item 17, $p<$ 0.001). Most of non-dental students reported brushing each tooth meticulously (Item 9); often checking their teeth in a mirror after brushing (Item 12), and that they had worries about their teeth color (Item 3) (Table 2). There were significant differences ( $p<$ 0.001 ) by year of dental education for using child-size toothbrush (Item 5), cleaning of the teeth without toothpaste (Item 11), and brushing very well told by their dentist (Item 20). There were not any significant differences between dental and non-dental students for worrying much about visiting the dentist (Item 1), using a child-size toothbrush (Item 5), cleaning teeth without toothpaste (Item 11), preventing periodontal diseases with solely tooth brushing (Item 14), and spending too much time for brushing (Item 18) (Table 2).

Most of the students among the total study population thought they would have dentures when they age and believed it was impossible to avoid periodontal diseases by merely tooth brushing.
A greater number of preclinical students thought that they will not be able to refrain from having dentures in old age (Item $6, p<$ $0.0001)$, and despite daily tooth brushing, their teeth were getting worse (Item $8, p<0.0001$ ) in comparison to clinical dental students. Additionally, a higher proportion of preclinical students stated that it was not possible to stay away from periodontal diseases by merely tooth brushing (Item 14. $p<0.0001$ ) and felt that they brushed well when they brushed hard (Item 18, $p<0.0001$ ).

Sixty-five percent of all students responded "agree" to the statement "I brush each of my teeth carefully". Eighty-nine percent of the entire study group said they often controlled their teeth in a mirror following brushing, whereas only $3 \%$ reported utilizing a child-sized toothbrush. Most of the clinical students said they brushed each of their teeth carefully (Item 9, $p<0.0001$ ). Only $43 \%$ of the total students said their dentist had told them that they brush their teeth well (Item 20, $p<0.0001$ ). When compared to clinical students, more preclinical students stated using a childsized toothbrush (Item 5, $p<0.05$ ), and/or a toothbrush with hard bristles (Item 17, $p<0.01$ ).

Eighty-one percent of all students reported that they did not worry much about visiting the dentist. Approximately $6 \%$ of students were concerned about the color of their gingiva. More clinical students than preclinical students reported gingival bleeding (Item 2, $p<0.0001$ ), whereas more preclinical students were annoyed with the color of their gums (Item 7, $p<0.0001$ ) and postponed going to the dentist until they had a toothache (Item $15, p<0.0001)$. More preclinical students were worried about the color of their teeth (Item $3, p<0.0001$ ) and having bad breath (Item $13, p<0.0001$ ) as well.

The scores reflecting oral health behaviors are calculated from the responses of 12 items of the HU-DBI (Table 2). The maximum possible score is 12 and better oral health behavior is indicated by higher scores. ${ }^{11}$ The mean HU-DBI score of the dental students was significantly higher than that of the non-dental students (6.15 vs $4.66 ; p<0.001)$. The mean scores for the preclinical and clinical students were 5.72 and 6.72 , respectively. The non-dental students were the least happy group with their appearance compared to the other two groups (Table 2).

Regarding the self-reported dental status, there were no significant differences between dental and non-dental students (Table 2). The average tooth loss was two teeth for all the groups. However, the number of teeth with fillings was slightly higher for the clinical students.

Table 3 presents the logistic regression model that predicts group membership. The final multivariate model contained ten items of the HU-DBI. Most of the dental students stated they had used a plaque disclosing dye (Item 16, OR 1.97, 95\% Cl 0.882-4.397). They stated that they were using a toothbrush with hard bristles (Item 177, OR 0.647, 95\% Cl 0.397-1.052) as well, and they were more concerned than non-dental students about the color of their teeth (Item 3, OR 0.616, 95\% Cl 0.394-0.963). Moreover, they reported that their dentists were satisfied with their brushing performance (Item 20, OR 0.611, 95\% Cl 0.373-1.003). It was shown that 227 clinical students (85\%) and 131 preclinical dental students (63\%) were correctly predicted by the model (Fig. 1). The overall correct classification rate was found out to be 0.75 , which is considerably higher than the expected rate of 0.5. The percentages of "agree" responses according to education level are shown in Table 3. Among 15 questions, 10 questions showed significant differences by year. 
Table 2: Questionnaire items of the HU-DBI and percentage of "agree" responses by level in the dental (preclinical and clinical) and non-dental students

\begin{tabular}{|c|c|c|c|c|c|c|c|}
\hline$H U-D B I$ item no & $\begin{array}{l}\text { Preclinic } \\
\text { students }\end{array}$ & $p$ value ${ }^{a}$ & $\begin{array}{l}\text { Clinic } \\
\text { students }\end{array}$ & $\begin{array}{l}\text { Dental } \\
\text { students }\end{array}$ & $p$ value $e^{b}$ & $\begin{array}{l}\text { Non-dental } \\
\text { students }\end{array}$ & $p$ value ${ }^{c}$ \\
\hline 1. I don't worry much about visiting the dentist & 66.9 & NS & 71.7 & 69 & NS & 65 & NS \\
\hline 2. My gums tend to bleed when I brush my teeth (D) & 13.3 & 0.036 & 6.2 & 10.1 & $p<0.001$ & 42.3 & $p<0.001$ \\
\hline 3. I worry about color of my teeth & 37.6 & 0.009 & 24.1 & 31.6 & $p<0.001$ & 58.6 & $p<0.001$ \\
\hline $\begin{array}{l}\text { 4. I have noticed some white sticky deposits on my } \\
\text { teeth }(A)\end{array}$ & 13.3 & NS & 12.4 & 12.9 & $p<0.001$ & 25.1 & $p<0.001$ \\
\hline 5. I use a child-sized toothbrush & 10.5 & $p<0.001$ & 42.1 & 24.5 & NS & 19 & NS \\
\hline $\begin{array}{l}\text { 6. I think that I cannot help having false teeth when I } \\
\text { am old (D) }\end{array}$ & 18.8 & NS & 11 & 15.3 & $p<0.001$ & 43.5 & $p<0.001$ \\
\hline 7. I am bothered by the color of my gums & 16 & NS & 11 & 13.8 & $p<0.001$ & 40.2 & $p<0.001$ \\
\hline $\begin{array}{l}\text { 8. I think my teeth are getting worse despite my daily } \\
\text { brushing (D) }\end{array}$ & 21.5 & 0.02 & 11.7 & 17.2 & $p<0.001$ & 37.5 & NS \\
\hline 9. I brush each of my teeth carefully (A) & 62.4 & 0.03 & 73.8 & 67.5 & $p<0.001$ & 52.3 & NS \\
\hline $\begin{array}{l}\text { 10. I have never been professionally taught how to } \\
\text { brush (D) }\end{array}$ & 51.4 & $p<0.001$ & 26.9 & 40.5 & 0.027 & 48.9 & NS \\
\hline $\begin{array}{l}11 . \text { I think I can clean my teeth without using } \\
\text { toothpaste }(\mathrm{A})\end{array}$ & 12.2 & $p<0.001$ & 31.7 & 20.9 & NS & 17.2 & NS \\
\hline $\begin{array}{l}\text { 12. I often check my teeth in a mirror after brushing } \\
\text { (A) }\end{array}$ & 86.7 & NS & 93.1 & 89.6 & 0.001 & 80.4 & NS \\
\hline 13. I worry about having bad breath & 53.6 & 0.039 & 42.1 & 48.5 & $p<0.001$ & 66.8 & NS \\
\hline $\begin{array}{l}\text { 14. It is impossible to prevent gum disease with } \\
\text { tooth brushing alone (D) }\end{array}$ & 75.7 & NS & 70.3 & 73.3 & NS & 79.8 & NS \\
\hline $\begin{array}{l}\text { 15. I put off going to the dentist until I have a } \\
\text { toothache (D) }\end{array}$ & 50.3 & 0.004 & 34.5 & 43.3 & $p<0.001$ & 82.2 & $p<0.001$ \\
\hline $\begin{array}{l}\text { 16. I have used a dye to see how clean my teeth are } \\
\text { (A) }\end{array}$ & 13.3 & NS & 11 & 12.3 & $p<0.001$ & 3.9 & $p<0.001$ \\
\hline 17. I use a toothbrush which has hard bristles & 23.8 & $p<0.001$ & 6.2 & 16 & $p<0.001$ & 31.4 & NS \\
\hline $\begin{array}{l}\text { 18. I don't feel I've brushed well unless I brush with } \\
\text { strong strokes }\end{array}$ & 24.9 & 0.003 & 11.7 & 19 & $p<0.001$ & 36.3 & $p<0.001$ \\
\hline $\begin{array}{l}\text { 19. I feel I sometimes take too much time to brush } \\
\text { my teeth (A) }\end{array}$ & 15.5 & NS & 17.9 & 16.6 & NS & 22.1 & NS \\
\hline $\begin{array}{l}\text { 20. I have had my dentist tell me that I brush very } \\
\text { well }\end{array}$ & 19.3 & $p<0.001$ & 49.7 & 32.8 & $p<0.001$ & 18.4 & NS \\
\hline 21. I am satisfied with the appearance of my teeth & 28.2 & $p<0.001$ & 69.7 & 46.6 & $p<0.001$ & 15.4 & NS \\
\hline
\end{tabular}

NS, not significant

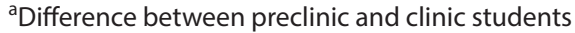

${ }^{\mathrm{b}}$ Difference between dental and non-dental students

'Difference between preclinic and non-dental students

\section{Discussion}

Oral health providers are expected to establish correct oral habits as a part of their profession in providing oral healthcare. Dental students are expected to have superior consciousness of oral self-care since this plays an important role in allowing them to define their patients' oral health and to create oral awareness. The development of individual oral health among dental students is connected to their improvement throughout their dental education. ${ }^{7,20,21}$ The present study has shown that, just as many other studies conducted with the HU-DBI, oral self-care attitudes improve with dental education., ${ }^{9} 15,19-26$

This study was the first evaluation of self-reported oral health attitudes and behaviors of dental and non-dental/medical students using the original HU-DBI. Therefore, it has prime importance. There are two studies to our knowledge that compared the data of dental students to that of students from other faculties. Both studies' results complied with ours. In Lithuania, 183 dental and 75 technology students were evaluated. They stated that oral health behaviors and knowledge of dental students were more advanced. ${ }^{27}$ Second, a study in Columbia compared dental students to civil engineering students where it was observed that dental education brings out significantly better outcomes. ${ }^{28}$ They used the Spanish version of the HU-DBI whereas, in our study, the English version was conducted. The interpretation of the HU-DBI from English to Turkish was required as a result of Turkish being the predominant language of teaching in most of the universities in our country, particularly the two universities that this study was performed. The outcomes revealed that the Turkish version of the HU-DBI was linguistically equivalent to the questionnaire in English.

The HU-DBI provides a numerical prediction of general oral health attitudes and behaviors depending on the total number 
Table 3: Results of backward multivariate logistic regression analysis for the dental and non-dental students (a) and the preclinic and clinic students ( $b$ and $c)$

\begin{tabular}{|c|c|c|c|c|c|c|c|c|}
\hline Item no & $B$ & Std. error & Wald & $d f$ & Sig. & $\operatorname{Exp}(B)$ & $\begin{array}{l}95 \% \text { Confidence interval } \\
\text { for } \operatorname{Exp}(B)\end{array}$ & \\
\hline \multicolumn{9}{|c|}{ (a) Dental and non-dental students } \\
\hline Intercept & 1.531 & 0.240 & 40.776 & 1 & 0.000 & & & \\
\hline 2 & -1.333 & 0.255 & 27.394 & 1 & 0.000 & 0.264 & 0.160 & 0.434 \\
\hline 3 & -0.485 & 0.228 & 4.521 & 1 & 0.033 & 0.616 & 0.394 & 0.963 \\
\hline 6 & -0.680 & 0.239 & 8.114 & 1 & 0.004 & 0.507 & 0.317 & 0.809 \\
\hline 7 & -0.842 & 0.254 & 10.962 & 1 & $0.001^{\mathrm{a}, \mathrm{b}}$ & 0.431 & 0.262 & 0.709 \\
\hline 15 & -1.234 & 0.219 & 31.837 & 1 & 0.000 & 0.291 & 0.190 & 0.447 \\
\hline 16 & 0.678 & 0.410 & 2.735 & 1 & 0.098 & 1.970 & 0.882 & 4.397 \\
\hline 17 & -0.436 & 0.248 & 3.088 & 1 & 0.079 & 0.647 & 0.397 & 1.052 \\
\hline 20 & -0.492 & 0.253 & 3.794 & 1 & 0.051 & 0.611 & 0.373 & 1.003 \\
\hline \multicolumn{9}{|l|}{ (b) Preclinic } \\
\hline Intercept & 0.890 & 0.270 & 10.834 & 1 & 0.001 & & & \\
\hline 2 & -1.207 & 0.275 & 19.313 & 1 & 0.000 & 0.299 & 0.175 & 0.512 \\
\hline 3 & -0.362 & 0.246 & 2.159 & 1 & 0.142 & 0.697 & 0.430 & 1.128 \\
\hline 6 & -0.705 & 0.260 & 7.344 & 1 & 0.007 & 0.494 & 0.297 & 0.823 \\
\hline 7 & -0.797 & 0.276 & 8.319 & 1 & 0.004 & 0.451 & 0.262 & 0.775 \\
\hline 10 & 0.441 & 0.224 & 3.877 & 1 & 0.049 & 1.554 & 1.002 & 2.411 \\
\hline 15 & -1.187 & 0.240 & 24.375 & 1 & 0.000 & 0.305 & 0.190 & 0.489 \\
\hline 16 & 0.897 & 0.432 & 4.319 & 1 & 0.038 & 2.453 & 1.052 & 5.719 \\
\hline 17 & -0.105 & 0.259 & 0.165 & 1 & 0.685 & 0.900 & 0.542 & 1.495 \\
\hline 20 & -0.731 & 0.287 & 6.491 & 1 & 0.011 & 0.481 & 0.274 & 0.845 \\
\hline \multicolumn{9}{|l|}{ (c) Clinic } \\
\hline Intercept & 0.552 & 0.313 & 3.108 & 1 & 0.078 & & & \\
\hline 2 & -1.666 & 0.424 & 15.430 & 1 & 0.000 & 0.189 & 0.082 & 0.434 \\
\hline 3 & -0.720 & 0.316 & 5.173 & 1 & 0.023 & 0.487 & 0.262 & 0.905 \\
\hline 6 & -0.741 & 0.370 & 4.014 & 1 & 0.045 & 0.477 & 0.231 & 0.984 \\
\hline 7 & -1.031 & 0.389 & 7.044 & 1 & 0.008 & 0.357 & 0.166 & 0.764 \\
\hline 10 & -0.361 & 0.287 & 1.581 & 1 & 0.209 & 0.697 & 0.397 & 1.224 \\
\hline 15 & -1.361 & 0.284 & 22.990 & 1 & 0.000 & 0.256 & 0.147 & 0.447 \\
\hline 16 & 0.305 & 0.497 & 0.376 & 1 & 0.540 & 1.356 & 0.512 & 3.594 \\
\hline 17 & -1.469 & 0.427 & 11.858 & 1 & 0.001 & 0.230 & 0.100 & 0.531 \\
\hline 20 & -0.158 & 0.310 & 0.259 & 1 & 0.611 & 0.854 & 0.466 & 1.567 \\
\hline
\end{tabular}

Items are defined in Table 2. Backward stepwise elimination with the likelihood-ratio criterion was used to select variables for removal. Variables entered on step 1: items number 1-20. Variables removed at step: $2=$ number $1.3=$ number $19.4=$ number $6.5=$ number $10.6=$ number $5.7=$ number $9.8=$ number $11.9=$ number $17.10=$ number $12.11=$ number 4

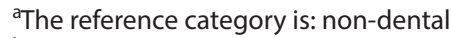

${ }^{\mathrm{b}}$ This parameter is set to zero because it is redundant

of suited agree/disagree responses. The maximum possible score is 12 , and higher scores indicate better oral health attitudes. ${ }^{5}$ The overall mean HU-DBI score of dental students was $6.17 \pm 1.7$ and non-dental/medical students was $4.66 \pm 1.8$. The scores of dental students were in accordance with the scores of dental students from several countries. $4,15,17,20,21,29-31$

The results of our study presented that, when compared with dental students, more of the non-dental/medical students had gingival bleeding and plaque accumulation $(p<0.001)$ (Item 2 , Item 4 , respectively). Likewise, more non-dental students than dental students thought that their teeth were getting worse and they would have dentures when they are old $(p<0.001)$ (Item 8 , Item 6 , respectively). Contrary to dental students, most of the non-dental/ medical students stated that they did not go to a dentist until they had a toothache $(p<0.001)$ (Item 15). This might be resulting from the oral health education that dental students receive during their higher education.

Table 2 shows that better percentages of expected answers were received from clinical dental students compared to preclinical students. These differences in attitudes indicate that dental students' behaviors improve with increasing levels of education. This was in compliance with other studies. ${ }^{12,15,25,29,32,33}$

The percentage of dental students (12.3\%) who reported that they used a plaque disclosing dye (Item 16) was more than that of non-dental/medical students (3.9\%). These percentages were very low compared with other studies since plaque indicating 


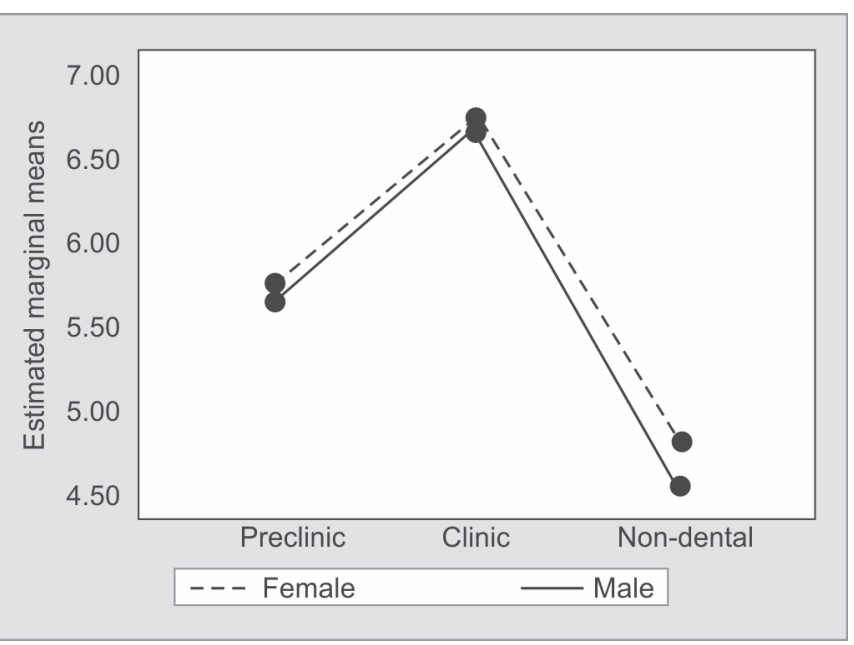

Fig. 1: Estimated marginal means of HU-DBI score according to gender and groups (no significant difference between the genders in the subgroups)

dyes are not regularly used in our country. 3,15,20,22,23,29 They are not a part of routine dental examination. They are generally used in Periodontology Clinics of Dental Faculties. Therefore, it might be anticipated that dental students are more likely to use these dyes during their education. Moreover, the percentage of dental students who brushed their each tooth carefully were more than that of non-dental/medical students (Item 9, $p<0.001$ ). The proportions of agreeing on responses to this Item of the survey were close to that of dental students from other studies. 2,14,16,20,25

Only $40.5 \%$ of dental students and $48.9 \%$ of non-dental/medical students stated that they had not been taught how to brush their teeth by a dentist (Item 10, $p=0.027$ ). These proportions were close to that of students from other studies conducted in Turkey, ${ }_{i}^{2,21,34}$ however, higher than Indian, ${ }^{20}$ Chinese and British, ${ }^{12}$ Greek and Japan, ${ }^{17}$ Jordanian, ${ }^{30}$ Lithuanian, ${ }^{27}$ and Iranian $^{32}$ dental students. Almost half of the population stating not having received any professional oral hygiene instruction may indicate the deficits in the dental health system or organization in Turkey since regular visits to a dentist and/or communal educational programs do not exist.

\section{Conclusion}

The fact that dental school students have better oral care habits (i.e., having less gum bleeding, noticing less plaque on their teeth, brushing each tooth carefully, visiting the dentist without a toothache, avoiding strong strokes when brushing, being less annoyed with the color of their gingiva) than non-dental/medical students may be explained by dental students' receiving dental curriculum and clinical training. Nevertheless, the outcomes of this study emphasize the comparatively poor oral health behaviors and attitudes of Turkish university students.

\section{Clinical Significance}

The insufficient oral health attitudes of Turkish university students should be enhanced with the help of generic national programs aiming at teaching oral healthcare and support individuals' oral hygiene practices as well as generalizing preventive oral health information; these programs must be applied beginning from early childhood.

\section{ACKNOWLEDGMENT}

The author would like to thank Prof Dr Cem Gurgan for all his contributions to the study. The author has declared that no financial support was received from any organization.

\section{References}

1. Martino S. Oral health behavioral and social intervention research concepts and methods. J Public Health Dent 2011;71:2-6. DOI: 10.1111/j.1752-7325.2011.00217.x.

2. Peker I, Alkurt MT. Oral health attitudes and behavior among a group of Turkish dental students. Eur J Dent 2009;3(1):24-31. DOI: 10.1055/s0039-1697402.

3. Rahman B, Kawas SA. The relationship between dental health behavior, oral hygiene and gingival status of dental students in the United Arab Emirates. Eur J Dent 2013;7(1):22-27. DOI: 10.1055/s-00391698991.

4. Lalani A, Dasar PL, Sandesh N, et al. Assessment of relationship between oral health behavior, oral hygiene and gingival status of dental students. Indian J Dent Res 2015;26(6):592-597. DOI: 10.4103/0970-9290.176922.

5. Halboub ES, Al-Maweri SA, Al-Jamaei AA, et al. Self-reported oral health attitudes and behavior of dental and medical students, Yemen. Glob J Health Sci 2016;8(10):143-150. DOI: 10.5539/gjhs.v8n10p143.

6. Al-Omari QD, Hamasha AA. Gender-specific oral health attitudes and behavior among dental students in Jordan. J Contemp Dent Pract 2005;6(1):107-114. DOI: 10.5005/jcdp-6-1-107.

7. Camgoz M, Gurgan CA, Kajiwara K, et al. Dental students' ability to assess gingival health status with DAAGS software. J Dent Educ 2008;72(1):59-66. DOI: 10.1002/j.0022-0337.2008.72.1.tb04453.x.

8. Al-Omiri MK, Barghout NH, Shaweesh Al, et al. Level of education and gender-specific self-reported oral health behavior among dental students. Oral Health Prev Dent 2012;1(1):29-35.

9. Lujo M, Meštrović M, Malčić Al, et al. Knowledge, attitudes and habits regarding oral health in first- and final-year dental students. Acta Clin Croat 2016;55(4):636-643. DOI: 10.20471/acc.2016.55.04.15.

10. Kawamura M. Dental behavioral science: the relationship between perceptions of oral health and oral status in adults [in Japanese]. J Hiroshima Univ Dent Soc 1988;20(2):273-286.

11. Levin $L$, Shenkman A. The relationship between dental caries status and oral health attitudes and behavior in young Israeli adults. J Dent Educ 2004;68(11):1185-1191. DOI: 10.1002/j.0022-0337.2004.68.11. tb03864.x.

12. Komabayashi T, Kwan SYL, Hu DY, et al. A comparative study of oral health attitude and behavior using Hiroshima University-dental behavioral inventory (HU-DBI) between dental students in Britain and China. J Oral Sci 2005;47(1):1-7. DOI: 10.2334/josnusd.47.1.

13. Kawamura M, Kawabata K, Sasahara H, et al. Dental behavioral science Part IX. Bilinguals' responses to the dental behavioral inventory (HUDBI) written in English and in Japanese. J Hiroshima Univ Dent Soc 1992;22:185-199.

14. Kawamura M, Wright FA, Declerck $D$, et al. An exploratory study on cultural variations in oral health attitudes, behavior and values of freshman dental students. Int Dent J 2005;55(4):205-211. DOI: 10.1111/j.1875-595x.2005.tb00317.x.

15. Kawamura $M$, Honkala $E$, Wildström $E$, et al. Cross-cultural differences of self-reported oral health behavior in Japanese and Finnish dental students. Int Dent J 2000;50(1):46-50. DOI: 10.1111/j.1875-595x.2000. tb00546.x.

16. Mekhemar M, Conrad J, Attia S, et al. Oral health attitudes among preclinical and clinical dental students in Germany. Int J Environ Res Public Health 2020;17(12):4253-4264. DOI: 10.3390/ijerph17124253.

17. Polychronopoulou A, Kawamura M. Oral self-care behaviors: comparing Greek and Japanese dental students. Eur J Dent Educ 2005;9(4):164-170. DOI: 10.1111/j.1600-0579.2005.00387.x.

18. Landis JR, Koch GG. The measurement of observer agreement for categorical data. Biometrics 1977;33(1):158-174. DOI: 10.2307/2529310. 
19. Kawamura M, Iwamoto $Y$, Wright FAC. A comparison of self-reported dental health attitudes and behavior between selected Japanese and Australian dental students. J Dent Educ 1997;61(4):354-360. DOI: 10.1002/j.0022-0337.1997.61.4.tb03125.x.

20. Dagli RJ, Tadakamadla S, Dhanni C, et al. Self-reported dental health attitude and behavior of dental students in India. J Oral Sci 2008;50(3):267-272. DOI: 10.2334/josnusd.50.267.

21. Peker K, Uysal O, Bermek G. Dental training and changes in oral health attitudes and behaviors in Istanbul dental students. J Dent Educ 2010;74(9):1017-1023. DOI: 10.1002/j.0022-0337.2010.74.9. tb04958.x.

22. Rong WS, Wang WJ, Yip HK. Attitudes of dental and medical students in their first and final years of undergraduate study to oral health behavior. Eur J Dent Educ 2006;10(3):178-184. DOI: 10.1111/j.16000579.2006.00415.x.

23. Sato M, Camino J, Oyakawa HR, et al. Effect of dental education on peruvian dental students' oral health-related attitudes and behavior. J Dent Educ 2013;77(9):1179-1184. DOI: 10.1002/j.00220337.2013.77.9.tb05590.x.

24. Okoh M, Enabulele J. Influence of clinical experience on oral health attitude and behaviour of dental students attending a Nigerian University. Odontostomatol Trop 2014;37(148):25-31.

25. Muthu J, Priyadarshini G, Muthanandam S, et al. Evaluation of oral health attitude and behavior among a group of dental students in Puducherry, India: a preliminary cross-sectional study. J Indian Soc Periodontol 2015;19:683-686.

26. Kim KJ, Komabayashi T, Moon SE, et al. Oral health attitudes/behavior and gingival self-care level of Korean dental hygiene students. J Oral Sci 2001;43(1):49-53. DOI: 10.2334/josnusd.43.49.
27. Pacauskiene IM, Smailiene D, Siudikienè J, et al. Self-reported oral health behavior and attitudes of dental and technology students in Lithuania. Stomatologija 2014;16(2):65-71.

28. Jaramillo JA, Jaramillo F, Kador I, et al. A comparative study of oral health attitudes and behavior using the Hiroshima University-dental behavioral inventory (HU-DBI) between dental and civil engineering students in Colombia. J Oral Sci 2013;55(1):23-28. DOI: 10.2334/ josnusd.55.23.

29. Alam Moheet I, Farooq I. Self-reported differences between oral health attitudes of pre-clinical and clinical students at a dental teaching institute in Saudi Arabia. Saudi Dent J 2013;25(4):149-152. DOI: 10.1016/j.sdentj.2013.07.001.

30. Al-Wahadni AM, Al-Omiri MK, Kawamura M. Differences in selfreported oral health behavior between dental students and dental technology/dental hygiene students in Jordan. J Oral Sci 2004;46(3):191-197. DOI: 10.2334/josnusd.46.191.

31. Badovinac A, Božić $D$, Vučinac I, et al. Oral health attitudes and behavior of dental students at the University of Zagreb, Croatia. J Dent Educ 2013;77(9):1171-1178. DOI: 10.1002/j.00220337.2013.77.9.tb05589.x.

32. Karem Hassan B, Jabbar Ali B, Mahmood Alwan A, et al. Self-reported oral health attitudes and behaviors, and gingival status of dental students. Clin Cosmet Investig Dent 2020;12:225-232. DOI: 10.2147/ CCIDE.S249708.

33. Neeraja R, Kayalvizhi G, Sangeetha P. Oral health attitudes and behavior among a group of dental students in Bangalore, India. Eur J Dent 2011;5(2):163-167. DOI: 10.1055/s-0039-1698874.

34. Yıldız S, Dogan B. Self-reported dental health attitudes and behavior of dental students in Turkey. Eur J Dent 2011;5(3):253-259. DOI: 10.1055/s-0039-1698889. 